\title{
Impact of Applied Potential on the Structural and Non-lubricated Wear Composite Coating in Petrochemical Industry
}

\author{
P.A.L. Anawe ${ }^{a}$ and O.S.I. Fayomi ${ }^{b, c, *}$ \\ ${ }^{a}$ Department of Petroleum Engineering, Covenant University, P.M.B. 1023, Ota, Nigeria \\ ${ }^{b}$ Department of Mechanical Engineering, Covenant University, P.M.B. 1023, Ota, Nigeria \\ ${ }^{c}$ Department of Chemical, Metallurgical and Materials Engineering, Tshwane University of \\ Technology, P.M.B. X680, Pretoria, South Africa
}

Received December 31, 2016; accepted March 31, 2017

\begin{abstract}
The need to improve the structural properties of materials in petrochemical industry, due to recurring failure, has motivated this study. The effect of deposition potential on structural integrity, surface topography and micromechanical progression of $\mathrm{Zn}$ based induced aluminium and $\mathrm{TiO}_{2}$ alloy coating series on mild steel was studied. The wear stability and microhardness behaviour of the developed composite coating was examined via, respectively, sliding reciprocating rig and dura scan diamond based microhardness tester. The structural reliability was inspected with scanning electron microscope equipped with EDS, and atomic force microscope. The results showed that the superb structural crystal resulted into a significant increase in the microhardness, and into a decrease in wear plastic deformation in a non-lubricated system. The precipitation of the deposits enforces stable crystal orientation and compact grains growth. The work has established that up to $13 \mathrm{wt} \% \mathrm{TiO}_{2}$ on zinc rich bath, a solid composite coating on mild steel, can be used to improve the service life of coating for stable structural properties.
\end{abstract}

Keywords: Applied potential; structural integrity; co-deposition; oil and gas.

\section{Introduction}

The successful use, over years, of engineering materials, especially mild steel, in construction, aerospace, automobile, and most especially in the oil and gas sector, has been massive, due to its inclusive properties. Its multifaceted importance on low cost, availability and ease of fabrication has also given it an edge on demand. Unfortunately, mild steel versatility has its limitations, as it has a low hardness tendency, increases plastic deformation and is prone to structural defect in high temperature applications [1-3].

\footnotetext{
*Corresponding author. E-mail address: ojosundayfayomi3@gmail.com_ojo.fayomi@covenantuniversity.edu.ng
} 
Several surface protection applications were used to continually improve the forbearing nature of steel challenges [4]. Electrodeposition is an appreciable technique that has been known to proffer superior advantage over other functional applications, mainly due to its excellent performance [5], although the challenge of co-deposition has been the stability and formation of bath, based on the nature of coating. The kind of bath constituents is known to influence the nature of coating, and it is stated that properties of binary alloy deposits are advantageous, based on the resilient characteristics of metal or composite embedded in the bath [6-7].

From the assertion made by [1-3] [8,9], the plating parameters such as current density, rate of agitation, temperature range, bath constituents' concentration and $\mathrm{pH}$, determine the fraction in which two or more metals uniformly co-deposit to have good surface modified coatings [10]. It is worth mentioning that a significant variation in any one parameter could require a substantial and rewarding alteration in another variable or combination of parameters, to maintain a given design and fabricated coating [1-3].

Metals associated with different complexing ions can significantly change in coating composition. More so, transition metal-oxides exhibit fascinating properties and multiple functionalities; and their sensitive nature provide improved microstructure, reinforced crystal grains and better mechanical properties for engineering application $[13,14]$.

In view of this, the effect of applied potential on the properties of the coating will be studied to test the wear and hardness behaviour of the developed alloys.

\section{Materials and method Materials}

A flat plate mild steel $(20 \mathrm{~mm}$ x $20 \mathrm{~mm}$ x $2 \mathrm{~mm}$ ) substrate was used in this study. Other materials employed for the purpose of this work include pure zinc plate anode, zinc chloride, glycine, thiourea, $\mathrm{Al}$ (45 nm, $97 \%$ purity) and tin IV oxide (25 nm, $99.7 \%$ purity).

\section{Method}

\section{Sample preparation}

The mild steel plate was sectioned using an automatic strewers high precision cut-off machine, which was connected to lubricant supply to cool the blade and sample during the cutting process. The mild steel plate was cut into equal plates of about five samples with dimensions of $20 \mathrm{~mm}$ by $20 \mathrm{~mm} \times 2 \mathrm{~mm}$.

\section{Electro-deposition}

The mild steel sample was dipped into a $1 \mathrm{M} \mathrm{HCl}$ solution for 10 seconds, followed by rinsing into the de-ionised water. Analytical grade chemicals and deionised water were used to prepare the plating solutions at $40{ }^{\circ} \mathrm{C}$, to easily dissociate any agglomerate in the bath. During the plating, the solutions were stirred at $200 \mathrm{rpm}$ using the magnetic stirrer, for the solution to plate well on the mild steel. The admixed bath compositions for the coatings are shown in Table 1, 
and they were prepared two weeks before the plating. Boric acid and other ingredients were added, and a $\mathrm{pH}$ of 4.5 was attained. A constant static current density was used to produce $\mathrm{Zn}-\mathrm{Al}-\mathrm{TiO}_{2}$ coating series. A current density of $1.0 \mathrm{~A} / \mathrm{cm}^{2}$ was used for the deposition at a varying voltage between $0.3-0.5 \mathrm{~V}$. The rinsing was done in distilled water for 5 seconds, and then later air dried.

Table 1. Summarized bath formulation.

\begin{tabular}{cc}
\hline Composition & Mass concentration $(\mathbf{g} / \mathbf{L})$ \\
\hline $\mathrm{Zn}$ & 75 \\
$\mathrm{Al}$ & 30 \\
$\mathrm{KCl}$ & 50 \\
Boric acid & 10 \\
$\mathrm{TiO}_{2}$ & $7-13$ \\
$\mathrm{ZnCl}$ & 75 \\
$\mathrm{pH}$ & 4.5 \\
Voltage & $0.3-0.5 \mathrm{~V}$ \\
Time & $20 \mathrm{~min}$. \\
Temp. & $40{ }^{\circ} \mathrm{C}$ \\
\end{tabular}

Table 2 shows the bath process formulation.

Table 2. Electrodeposition parameters for deposited coatings.

\begin{tabular}{ccccccc}
\hline Sample & $\begin{array}{c}\text { Time } \\
(\mathbf{m i n})\end{array}$ & $\begin{array}{c}\text { Voltage } \\
(\mathbf{V})\end{array}$ & $\begin{array}{c}\text { Additive } \\
\text { concentration } \\
(\mathbf{g})\end{array}$ & $\begin{array}{c}\text { Coating } \\
\text { thickness } \\
(\boldsymbol{\mu m})\end{array}$ & $\begin{array}{c}\text { Weight } \\
\text { gain }(\mathbf{g})\end{array}$ & $\begin{array}{c}\text { Coating } \\
\text { per unit } \\
\text { area } \\
\left(\mathbf{m g} / \mathbf{m m}^{2}\right)\end{array}$ \\
\hline $\mathrm{Zn}-\mathrm{Al}-\mathrm{Ti}-\mathrm{Cl}$ & 20 & 0.3 & 7 & 114.6 & 0.2077 & 0.0366 \\
$\mathrm{Zn}-\mathrm{Al}-\mathrm{Ti}-\mathrm{Cl}$ & 20 & 0.5 & 7 & 153.1 & 0.2274 & 0.0270 \\
\hline
\end{tabular}

\section{Characterization of the electrodeposited samples}

The structural properties of the sample were examined by scanning using a JEOL JSM 6390 electron microscope. An Emco-test micro-hardness tester machine was used to determine the hardness values of the samples. Indentation of five points and 15 seconds dwell with $100 \mathrm{~g}$ load were used in this work.

\section{Reciprocating wear test}

Reciprocating ball-on-flat sliding wear tests were performed on a CETR UMT-2 tribometer. For sliding wear tests, a 20 x $20 \mathrm{~mm}$ coated mild steel substrate was cut, and an aluminum ball of $10 \mathrm{~mm}$ diameter was engaged as counterface. The tests were performed under a load of $5 \mathrm{~N}$ with a distance of $2.000 \mathrm{~m}$, oscillating frequency of $5 \mathrm{~Hz}$, and wear stroke length of $2 \mathrm{~mm}$. The tests were carried in both dry sliding conditions. All tests were carried out at room temperature. The average wear depths of the samples at the end were used to evaluate the dry sliding wear performance. 


\section{Results and discussion}

\section{Characterization of the substrate}

The substrate metal used in this study is mild steel. The spectrometer chemical composition is detailed in Table 3. From the steel elemental evaluation, Fe is the major constituent with over $99 \%$, and there is a carbon content of approximately $0.15 \%$, among other visible elements in attendance. The average over all percentage of other metals is at minute quantity. The SEM structure of the working steel is shown in Fig. 1 with clearly prepared surface appearance.

Table 3. Chemical composition of as-received mild steel.

\begin{tabular}{ccccccccc}
\hline Element & $\mathbf{C}$ & $\mathbf{M n}$ & $\mathbf{S i}$ & $\mathbf{P}$ & $\mathbf{S}$ & $\mathbf{A l}$ & $\mathbf{N i}$ & $\mathbf{F e}$ \\
\hline Composition & 0.15 & 0.45 & 0.18 & 0.01 & 0.031 & 0.005 & 0.008 & Balance \\
\hline
\end{tabular}

\section{Properties and characteristics of deposited alloys}

Fig. 1a and $\mathrm{b}$ shows the SEM of the as-received and the deposited alloy at Zn-Al7Ti-0.5 V. The presence of process parameter is obvious on the produced alloy, with distinctive crystal growth and homogenous dispatched grains. More so, the coating appears to have a strong bond beneficial effect on $\mathrm{TiO}_{2}$ and aluminium in adequate concentration, which promotes the adhesion behaviour and interlock seen at the interface of the alloyed coating.

a)

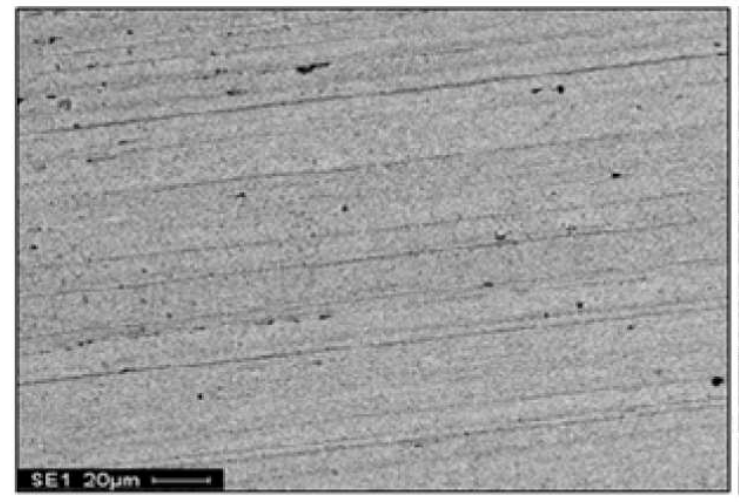

b)

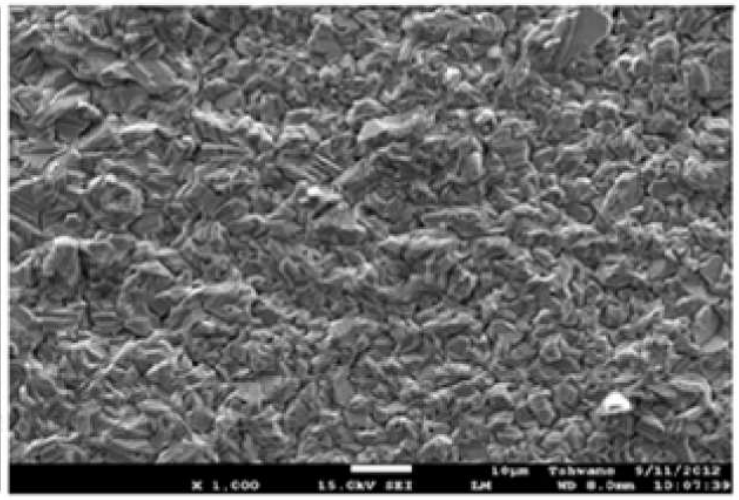

Figure 1. SEM/EDS spectra of a) the un-deposited mild steel and b) Zn-Al-7Ti-0.5 V.

No doubt that the structural differences maximally depend on the embedded volume of the particulate in the deposit and the corresponding applied potential which, in turn, gives smaller regular grains, without porosity. More so, it is worth mentioning that particles cannot provide preferential nucleation vacancies for the next stage layer of deposition, without the effort of Zn-based sample, which often results into crystal buildup, leaving the particulate to gain a robust structural cohesion with other composite. Fig. 2 shows the adhesion characteristic and topography of $\mathrm{Zn}-\mathrm{Al}-\mathrm{TiO} 2$ composite, as against the as-received samples. From the presented structure, it is clear that the as-received sample has no evidence of crystal growth; see Fig. 2a. With Zn-Al-7TiO2-0.5 V alloy coating, a compact fine topography, which connotes deposit profile, was seen at the surfaces. This is in line with the study made by [5]. 
In addition, the deposited layer has some micro-crystallites hexagonal flakes with uniform distribution and slight agglomeration, which, to some extent, contribute to the topographic properties of $\mathrm{Zn}-\mathrm{Al}-7 \mathrm{TiO} 2-0.5 \mathrm{~V}$ coating and could influence its performance characteristics. $-7 \mathrm{TiO}_{2}-0.5 \mathrm{~V}$ coating and could influence its performance characteristics.

(a)

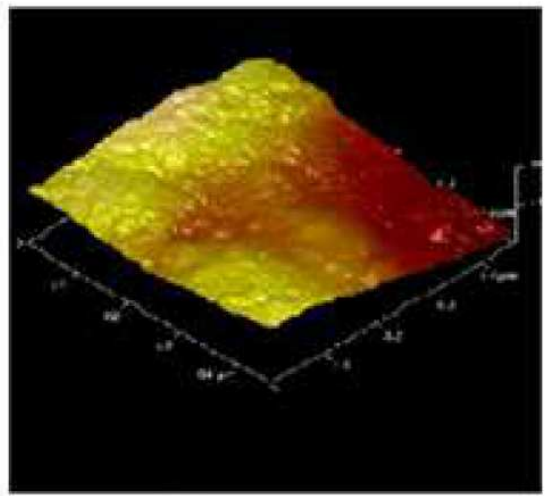

As-received

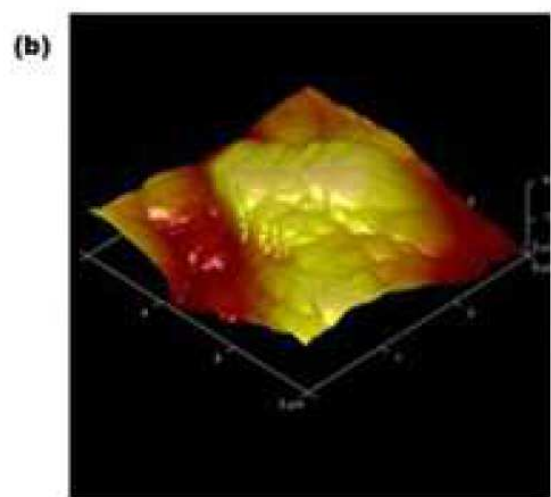

Zn-AI-TTi-0.5V

Figure 2. AFM images of (a) as-received and (b) Zn-Al-7Ti-0.5 V.

Fig. 3 shows the progression of developed coatings on the hardness. From the chart, it is clear that there is an improved microhardness trend for the composites coated samples, as against the mild steel substrate, although applied potential was seen to actually determine the trend of the improvement of the hardness characteristics of the coating. It is obvious that the impediment and the combined effect of $\mathrm{TiO}_{2}$ with aluminum metal provoked decreases in crystallites size, resulting in a strong crystallite distributed across the entire surfaces, which invariably gives solid hard layers.

Agreeing to [8, 9], titanium composite particles incorporated in $\mathrm{Zn}$ matrix can act as seeds for the whiskers growth; [10] added that, through a strengthening mechanism, either via dispersion strengthening or particle strengthening, the whiskers growth will invariably result into higher microhardness. From all these indications, coatings with Zn-Al-7Ti-0.5 V-Cl (289.6 HVN), with higher microhardness value, follow the above assertion. With lesser potentials, Zn-Al-7Ti-0.3 $\mathrm{V}-\mathrm{Cl}$ has 193.4 HVN hardness performance. The microhardness of the mild steel is approximately $34 \mathrm{HVN}$; this implies that all composite produced coatings had a significant impact on the mild steel improvement.

Fig. 4 shows the compressive wear mass loss of coatings as against the asreceived mild steel substrate. The result of the wear assessment shows a progressive trend, as that of the hardness behaviour correspondent. From all observations, the structural evolution is seen to significantly impact on the inclination tendency of plastic deformation, although $[5,6]$ mentioned that the control of microstructure plays a vital role on the wear movement, as seen in Fig. 4. The effort of process parameter, especially the applied potential, could be seen to significantly influence the wear performance. A coating composite fabricated with $\mathrm{Zn}-\mathrm{Al}-7 \mathrm{Ti}-0.5 \mathrm{~V}-\mathrm{Cl}$ processed an average wear resistance of about 0.3 
$\mathrm{g} / \mathrm{min}$, as against the as-received sample, with massive wear plastic deformation of $2.351 \mathrm{~g} / \mathrm{min}$. The maximum wear loss is $0.4 \mathrm{~g} / \mathrm{min}$ for $\mathrm{Zn}-\mathrm{Al}-7 \mathrm{Ti}-0.3 \mathrm{~V}-\mathrm{Cl}$.

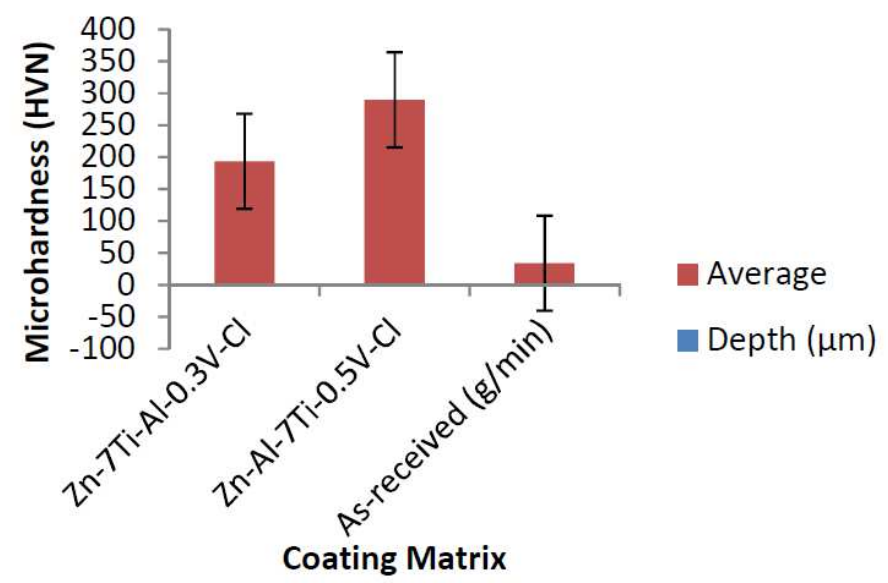

Figure 3. Microhardness chart for Zn-Al-Ti-Cl deposition.

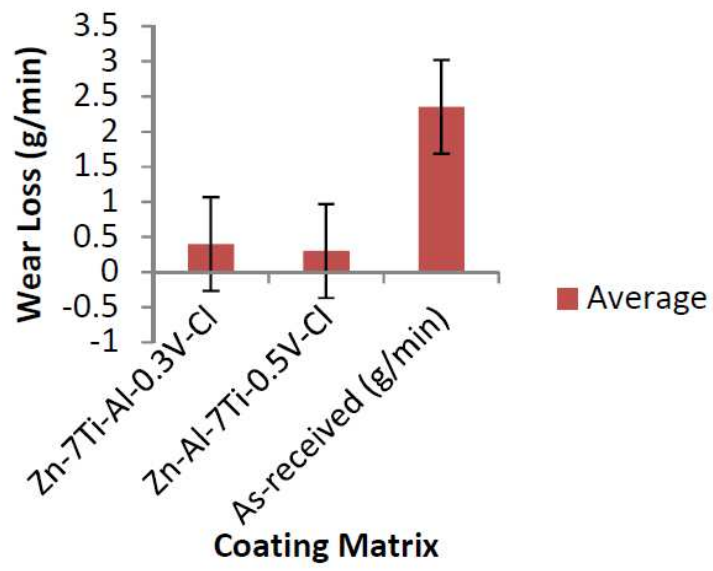

Figure 4. Wear mass loss movement of coatings.

\section{Conclusions}

- The co-deposition of chloride alloy was successful, with evidence of good structural properties.

- The structural build up results into significant wear and hardness integrity.

- The incorporation of $\mathrm{Al}-\mathrm{TiO}_{2}$ series into the $\mathrm{Zn}$ coating also creates a superior surface active topography needed for a cohesive coating, which massively contributes to the attained improved coating performance.

\section{References}

1. Fayomi OSI, Popoola API. An Investigation of the Properties of Zn Coated Mild Steel. Int J Electro Sci. 2012;7:6555-6570.

2. Lee CK. Wear and Corrosion Behavior of Electrodeposited Nickel-Carbon Nanotube Composite Coatings on Ti-6Al-4V Alloy in Hanks Solution. Trib Inter. 2012;55:7-14. 
3. Gomes A, Frade t, Nogueira ID. Morphological Characterization of ZnBased Nanostructured Thin Films. Current Micro Con. Adv Sci Tech. 2012;2:1146-1153.

4. Fayomi OSI, Popoola API. Chemical Interaction, Interfacial Effect and Microstructural Characterization of the Induced Zinc-Aluminuim -Solanium Tuberosum in Chloride Solution on Mild Steel. Res Chem Int. 2013;39:13541564.

5. Popoola API, Aigbodion VS, Fayomi OSI. Surface characterization, mechanical properties and corrosion behaviour of ternary based $\mathrm{Zn}-\mathrm{ZnO}-$ $\mathrm{SiO}_{2}$ composite coating of mild steel. J Alloys Compd. 2016;654:561-566.

6. Shanaghi A, Sabour AR, Shahrabi T, et al. Corrosion Protection of Mild Steel by Applying $\mathrm{TiO}_{2}$ Nanoparticle Coating via Sol-Gel Method. Prot Met Phys Chem Surf. 2009;45:305-311.

7. Vathsala K, Venkatesha TV. Zn- $\mathrm{ZrO}_{2}$ Nanocomposition and Evaluation of Corrosion Resistance. J Appl Surf Sci. 2011;257:8929-8936.

8. Popoola ASI, Fayomi OSI, Popoola OM. Comparative studies of microstructural, tribological and corrosion properties of plated $\mathrm{Zn}$ and $\mathrm{Zn}$ Alloy coatings, Int. J. Electrochem Science. 2012;7:4860-4870.

9. Fayomi OSI, Popoola API, Olorunniwo OE. Structural and properties of Zn$\mathrm{Al}_{2} \mathrm{O}_{3}-\mathrm{SiC}$ nano-composite coatings by direct electrolytic process. Int $\mathrm{J} \mathrm{Adv}$ Manuf Technol. 2016;87:389-398.

10. Fayomi OSI, Popoola API, Oloruntoba DT, Nanoparticle Dispersion, Microstructure and Thermal Effect of Multi-doped $\mathrm{ZrO}_{2} / \mathrm{SiC}$ from Sulphate Induced Electrolyte. Prot Met Phys Chem Surf. 2016;52:512-516.

11. Zhu X, Cai C, Zheng G, et al. Electrodeposition and Corrosion Behaviour of Nanostructured Ni-TiN Composite Films. Trans. Non Ferr Met Soc China. 2011;21: 2216-2224.

12. Arici M, Nazir H, Aksu A. Investigation of Sn-Zn Electrodeposition from Acidic Bath on EQCM. J Alloys Compd. 2011;509:1534-1537.

13. Popoola API, Fayomi OSI, Popoola OM. Electrochemical and Mechanical Properties of Mild Steel Electro-plated with Zn- Al. Int J Electro Sci. 2012;7:4898-4917.

14. Praveen BM, Venkatesha TV. Electrodeposition and Properties of Znnanosized $\mathrm{TiO}_{2}$ Composite Coatings. Appl Surf Sci. 2008;254:2418-2424. 